\author{
Cadernos de \\ ESTUDOS LINGUÍSTICOS - (59.3), Campinas, pp. 581-597 - set./dez. 2017
}

\title{
FONOLOGIA E ESCRITA: POSSÍVEIS RELAÇÕES E DESAFIOS TEÓRICO-METODOLÓGICOS
}

\author{
LUCIANI ESTER TENANI* \\ (UNESP)
}

\begin{abstract}
RESUMO: Este artigo trata de estudos sobre fonologia e escrita visando a dois objetivos. Um objetivo é tecer uma breve retrospectiva de estudos que, pioneiramente na década de 1980, traçaram possíveis caminhos de investigação; o segundo objetivo, ao primeiro associado, é demonstrar desenvolvimentos alcançados por pesquisas feitas posteriormente, notadamente, nas primeiras décadas de 2000. É dado destaque aos estudos que tomam as segmentações não-convencionais de palavra (como "de mais", "concerteza") de uma perspectiva linguística que as concebe como hipóteses dos escreventes acerca dos limites de palavras, construídas a partir de relações entre fala e escrita, reveladoras de (possíveis) interações entre informações de natureza prosódica, morfossintática e semântica dos enunciados. São analisadas grafias não-convencionais de palavras produzidas por alunos em processo de aquisição e de desenvolvimento de escrita em ambiente escolar. Argumenta-se a favor de uma abordagem segundo a qual dados de escrita são fonte para problematização de assunções que embasam teorias fonológicas.
\end{abstract}

Palavras-chave: fonologia, prosódia, escrita.

ABSTRACT: This paper deals with studies about phonology and writing, aiming at two objectives. One objective is to draw a brief retrospective of pioneering studies in the 1980 s which outlined possible paths of investigation, whereas the second objective, related to the first one, is to show developments achieved by subsequent research work done mainly in the first decades of the 2000s. We highlight studies which investigate the unconventional segmentation of words (such as "de mais" [too much], "concerteza" [certainly]) from a linguistic perspective conceiving them as students' hypotheses about word boundaries. These hypotheses are built from relations between speech and writing and reveal (possible) interactions between prosodic, morphosyntactic and semantic information about utterances. Our analysis comprises elementary school texts written by students in the process of acquisition and development of writing in a school environment. We argue in favour of an approach in which writing data provides the foundation for questioning assumptions which support phonological theories.

Keywords: phonology, prosody, writing.

* Professora Livre-docente do Departamento de Estudos Linguísticos e Literários na UNESP, câmpus de São José do Rio Preto, com atuação na área de Fonética e Fonologia do Português.lutenani@ibilce.unesp.br 


\section{INTRODUÇ̃̃O}

Neste artigo, trato da relevância de estudos de cunho fonético-fonológico para descrição e interpretação de registros escritos que não seguem as convenções ortográficas, notadamente aqueles produzidos em ambiente escolar, nos vários ciclos da educação básica no Brasil. Dentre os vários tipos de grafias, restrinjo-me às chamadas segmentações não-convencionais de palavras, quer as hipossegmentações, como "concerteza", quer as hipersegmentações, como "da quela". A restrição a essas grafias não-convencionais se deve, em parte, à complexidade linguística da noção de palavra, aos desafios teórico-analíticos envolvidos na descrição dessas grafias e, doutra parte, aos desenvolvimentos alcançados pelas pesquisas que perseguem rastros do processo de aquisição (e desenvolvimento) da escrita, sobre as quais trataremos mais à frente.

Inicialmente, cabe esclarecer que as reflexões aqui desenvolvidas são inspiradas em Abaurre (1996), para quem duas possíveis perspectivas poderiam ser adotadas quando tematizada a relação entre teorias linguísticas e dados da chamada escrita inicial, a saber: uma perspectiva "tranquila", segundo a qual as teorias linguísticas seriam suficientes para descrever e explicar os primeiros registros escritos infantis, e outra "de 'perplexidade' ante os dados - muitas vezes idiossincráticos e misteriosos - da escrita inicial" (ABAURRE, 1996, p. 112; grifos no original). A pesquisadora adota a segunda perspectiva ao tratar de sistematicidade, variabilidade e singularidade dos dados de escrita e, a partir desses dados, problematizar aspectos de teorias linguísticas.

Adotando essa perspectiva, segundo a qual "os dados da aquisição da escrita podem vir a constituir-se em fonte de renovação epistemológica para a própria teoria linguística" (ABAURRE, 1990), esboço, na próxima seção, o cenário em que nascem as primeiras reflexões em que teorias fonológicas são mobilizadas na descrição e análise de dados de escrita inicial, particularmente dados de segmentação não-convencional de palavra. Em seguida, explicito em que medida esse tipo de dado de escrita é relevante para validar e/ou problematizar assunções de teorias fonológicas, notadamente aquelas que têm por objetivo descrever e explicar a organização prosódica dos enunciados. A partir dessa problematização, aponto avanços e desafios teórico-analíticos para o campo da aquisição da escrita, notadamente para as investigações que abordam temas como aspectos da relação entre fala e escrita, em particular, por meio da análise dos chamados erros ortográficos relacionados à fronteira de palavras. Por meio dessa organização, tenho por objetivo lançar luz às contribuições e, por extensão, aos frutos acadêmicos que ainda são colhidos sobre a temática fonologia e escrita, inicialmente desenvolvida no Instituto de Estudos da Linguagem, UNICAMP. 


\section{RELEVÂNCIA DE DADOS DE SEGMENTAÇÃO DE PALAVRA: RETOMANDO OS PRIMEIROS ESTUDOS}

Nesta seção, caracterizo o conjunto de estudos realizados sobre segmentação não-convencional de palavra segundo abordagens linguísticas, com o objetivo de situar o presente artigo nesse conjunto. Para tanto, explicito bases comuns a pesquisas feitas no campo da Linguística, particularmente na área de Fonética e Fonologia, que tomam essas grafias como evidências de que unidades ritmoentoacionais da fala seriam, em alguma medida, plasmadas na escrita (ABAURRE, 1988b, 1991a, b; ABAURRE; SILVA, 1993; SILVA, 1991), além de funcionarem como pistas das relações sujeito e linguagem (ABAURRE, 1996; CAPRISTANO, 2007a, b; CHACON, 2005, 2006).

Essa abordagem linguística dada às segmentações não-convencionais de palavra nasce de reflexões sobre temas mais amplos acerca da alfabetização, feitas na década de 1980 no Brasil, ${ }^{1}$ período marcado pela proliferação de propostas alternativas ao ensino da escrita feito, até então, com base em cartilhas. ${ }^{2}$ As várias propostas buscavam enfrentar, principalmente, os baixos índices de alfabetização, somados a altos índices de reprovação no Ensino Fundamental (doravante, EF), verificados em todo o país.

Nessa mesma década, outro marco importante para os estudos sobre alfabetização, em particular, e o ensino da escrita, de modo amplo, foi a publicação, no Brasil, de Psicogênese da Língua Escrita, por Emília Ferreiro e Ana Teberosky. A pesquisa, feita no campo da Psicologia, de linha cognitivista, baseada em Jean Piaget, consiste numa particular explicitação do processo de aquisição da escrita, dando-se ênfase à capacidade cognitiva de aprendizagem da criança. ${ }^{3}$ Muitas pesquisas, desde então, são desenvolvidas (no Brasil, na Argentina, no México, principalmente) com o objetivo de determinar o que a criança já sabe sobre escrita quando entra na escola (na época, obrigatoriamente no primeiro ano do EF) e que estratégias (cognitivas) ela usa para desenvolver o que, nessa perspectiva, se entende como suas habilidades de leitura e escrita.

1 Exemplos dessas reflexões encontram-se nos Anais do Seminário Multidisciplinar de Alfabetização (1984), realizado pela Pontifícia Universidade Católica de São Paulo em parceria com o Instituto Nacional de Estudos e Pesquisas Educacional, do Ministério de Educação e Cultura, em 1983.

${ }^{2}$ Vale mencionar que essa proliferação de propostas decorre, fortemente, de esse período ser caracterizado pela chamada redemocratização da educação, após o fim da ditadura militar, fato que tem como consequência a volta de exilados, como Paulo Freire, o que fomenta não apenas reflexões sobre os rumos da educação no país, mas chega à implantação de propostas em redes públicas de ensino.

${ }^{3}$ Dentre outros aspectos importantes, essa tese teve como efeito deslocar a questão central da alfabetização dos métodos de ensino (sintético, analítico, global etc.), por meio dos quais o professor desempenhava papel principal, para o processo de desenvolvimento cognitivo que leva à aprendizagem (cf. FERREIRO; TEBEROSKY; 1999, p. VIII), em que a criança passa a ter papel principal. Embora não consistisse em um método de ensino, os conceitos e as reflexões propostas por Ferreiro e Teberosky (1999) deram origem ao chamado método construtivista. 
Pesquisas interessadas na aquisição da escrita proliferaram não apenas na área da Psicologia ou da Educação, mas, no Brasil, também na área da Linguística, sobretudo na subárea da Aquisição da Linguagem, uma vez que são temas centrais nessa subárea investigar a aquisição da língua materna e a aquisição da escrita (cf. SCARPA, 2001). ${ }^{4}$ Também se verificaram pesquisas sobre a mesma temática na subárea da Psicolinguística, que se particulariza por investigar relações entre organização de sistemas linguísticos e organização de pensamento e, naturalmente, caracteriza-se como um campo interdisciplinar, entre Psicologia e Linguística (cf. BALIEIRO JR., 2001).

Os estudos sobre aquisição da escrita, em particular, feitos na segunda metade da década de 1980 no Brasil, têm traços dessa interdisciplinariedade, além de traços de diversidade de abordagens teóricas advindas tanto da Linguística, quanto da Psicologia. Dentre a diversidade de abordagens, identificam-se, por exemplo, pesquisas ancoradas em princípios da Teoria Gerativista, que define como questão central para os estudos linguísticos explicar a competência linguística (que compreende investigar relação entre mente e linguagem, cf. CHOMSKY, 2009), ao lado de pesquisas que mobilizam fundamentos da abordagem Sócio-interacionista ${ }^{5}$ ou da Teoria Histórico-Cultural, baseadas nos estudos de Vygotsky (1988) sobre a relação entre pensamento e linguagem (cf. SCARPA, 2001).

Em meio a essa diversidade de pesquisas desenvolvidas sob várias vertentes teóricas interessadas em explicar a aquisição da linguagem, a escrita produzida na fase inicial do Ensino Fundamental ganhou o interesse de linguistas que investigavam aspectos fonéticos e fonológicos do português, por exemplo, pois as produções escritas iniciais se mostraram como fonte de dados relevantes para as teorias linguísticas, de modo amplo, e para as teorias fonológicas, de modo específico, como argumenta Abaurre (1988a, 1996).

Nesse cenário, explicitam Abaurre et al. (1984) e Abaurre (1988a) a relevância da produção escrita realizada espontaneamente, pois, nesse tipo de texto, as crianças registrariam suas hipóteses sobre a escrita, a partir de relações que estabeleceriam entre fala e escrita. Vale destacar que Abaurre et al. (1984, p. 25) defendem a importância da chamada produção espontânea da criança em oposição à produção de ditados ou cópias (predominantes no início da alfabetização) por se constituírem em produções significativas, tal como quando produzem enunciados falados espontaneamente. Ao tomar o texto espontâneo como objeto de análise, uma das questões de investigação passou a ser a segmentação do texto em palavras. O interesse por esse aspecto gráfico voltou-se, predominantemente, para a descoberta de quais critérios linguísticos guiariam as crianças no reconhecimento dos limites de palavras escritas.

\footnotetext{
${ }^{4}$ Mais especificamente, dados da aquisição da linguagem são fonte empírica importante para validar teorias linguísticas ou fazer avançar modelos teóricos que formalizam como crianças aprendem a falar sua língua materna e/ou uma segunda língua.

${ }^{5}$ Lemos (1984) explicita o que entende como avanços da abordagem piagetiana sobre alfabetização feita por Emília Ferreiro e seguidores e critica essa proposta, tomando por base noções advindas dos estudos conduzidos por Vygotsky, para defender uma abordagem sócio-interacionista da aquisição da escrita.
} 
Interessada por dados de segmentação não-convencional, Abaurre (1988a) sinaliza a importância da relação entre fala e escrita, para compreensão das hipóteses infantis acerca dos limites de palavra. A autora posiciona-se contrariamente à crença de que, nas primeiras produções escritas, as crianças tenderiam a escrever do modo como falam (visão que não foi completamente superada nos dias atuais) e afirma que "ninguém se programa para simplesmente 'escrever como fala', seja em termos de uso das letras e das suas relações com o som, seja em termos de segmentação, seja em termos das próprias estruturas linguísticas" (ABAURRE, 1988a, p. 137; destaques acrescentados).

Comungar dessas considerações de Abaurre (1988a) sobre a relevância de dados não-convencionais de escrita, como os de segmentação de palavra aqui abordados, implica mobilizar teorias linguísticas que tratem da complexa relação entre fala e escrita. Dentre as possíveis abordagens dessa relação, embora seja (ainda) predominante que os chamados erros ortográficos decorram de uma (indesejada) interferência de característica da fala na escrita, outra perspectiva tem embasado os estudos de aquisição (e desenvolvimento) da escrita. Nessa outra perspectiva, Corrêa (2004) concebe que fala e escrita se constituem de modo heterogêneo. Um dos argumentos apresentados pelo autor, relevante para a presente discussão, está no fato de que a escrita é constituída da fala já em sua gênese, uma vez que a escrita alfabética em sua materialidade gráfica representa o fônico. Embora a escrita ortográfica não seja uma mera representação do fônico de uma dada língua (por também ser motivada em características morfossintáticas e semânticas), sempre traz na representação (verbo-visual) dos enunciados suas características fonológicas. Dessa perspectiva, a base semiótica da escrita não é exclusivamente constituída de uma materialidade gráfica (de natureza visual), pois as letras (e também os sinais de pontuação) representam características fonético-fonológica de uma dada língua; ${ }^{6}$ portanto, a escrita é concebida como heterogeneamente constituída.

Noutra perspectiva, vale lembrar que a fala também apresenta uma dimensão visual, quando considerados resultados de experimentos psicolinguísticos sobre processamento perceptual da fala. Esses experimentos têm demonstrado que os gestos articulatórios são de natureza fônica e também visual e que a fala é um evento auditivo, proprioceptivo e visual integrado (SEKIYAMA; BURNHAM, 2004). A consequência dessa constatação, de nossa perspectiva, é assumir, para uma sociedade letrada, a constituição heterogênea da materialidade da fala, na medida em que dimensões fônica (acústico-articulatória), proprioceptiva e visual (articulatória) a constituem (TENANI, 2016, p. 122). Portanto, a fala também seria constituída de uma dimensão visual da linguagem.

Admitidas as constituições heterogêneas da fala e da escrita ora brevemente reportadas, passa a ser um desafio teórico-metodológico investigar relações entre fala e escrita e, especialmente, dados de escrita que parecem (sempre) mobilizar concomitantemente essas relações, especialmente características fônicas e gráficas de enunciados falados e escritos.

\footnotetext{
${ }^{6}$ Para outros argumentos em favor da concepção heterogênea da escrita, ver Corrêa (2004).
} 
Um tipo de dado de escrita que constitui fonte instigante para se tratar de questões que interessam às teorias fonológicas são as segmentações nãoconvencionais de palavra. Com efeito, as grafias das fronteiras de palavras podem ser indícios importantes na "validação das unidades prosódicas propostas nos modelos fonológicos não-lineares como constitutivas de uma hierarquia que reconhece vários domínios prosódicos como significativos em termos das representações fonológicas subjacentes" (ABAURRE, 1991a, p. 204). Sob esse viés investigativo, tem sido desenvolvida parte dos estudos dos grupos de pesquisa Estudos sobre a Linguagem (GPEL/UNESP/CNPq) e Estudos sobre a Aquisição da Linguagem Escrita (GEALE/UFPel/CNPq).

Destaca-se que os trabalhos realizados por ambos os grupos têm demonstrado - com base em bancos de textos escritos por crianças e adolescentes - em que medida grafias não-convencionais de palavra ${ }^{8}$ são reguladas, de modo complexo, por estruturas fonológicas que não se restringem aos constituintes sílaba e palavra (prosódica). Em Silva e Tenani (2014, p. 23-51), encontra-se resenha detalhada do conjunto desses trabalhos de modo que ficam evidenciados os avanços alcançados sobre a caracterização de estruturas fonológicas relevantes para compreender a aquisição da escrita, principalmente na fase delimitada pelos anos iniciais do EF.

Dos estudos realizados, retomo aqueles que me permitem estabelecer relações entre características da segmentação não-convencional no EF I e aquelas do EF II, tendo essas últimas como ponto de partida para comparação com as primeiras. Por meio dessa comparação, é possível demonstrar que não apenas dados de escrita inicial, mas também dados de desenvolvimento da escrita, fornecem importantes evidências da interação complexa entre informações fonológicas, morfossintáticas e semânticas quando da produção do enunciado escrito.

Em Tenani (2011a, b), encontram-se análises de segmentações nãoconvencionais de palavra identificadas em amostra transversal de textos do EF II seguidas de comparação entre os resultados sobre segmentações nãoconvencionais de palavra no EF I descritos, principalmente, por Capristano (2007a,b) e Chacon $(2005,2006)$, por esses autores partilharem dos mesmos

\footnotetext{
${ }^{7}$ Sobre segmentação não-convencional de palavras e sua relação com características fonológicas, encontram-se, no âmbito do GEALE, os seguintes trabalhos: Cunha (2004, 2010), Ferreira (2011), Cunha e Miranda (2013). No âmbito do GPEL, além dos trabalhos de Capristano (2004, 2007a, b), Chacon (2004, 2005, 2006, 2011), Tenani (2004, 2009, 2010, 2011a, b) já citados, foram produzidos artigos e dissertações: Capristano e Ticianel (2014), Silva e Tenani (2014); Tenani e Paranhos (2011), Paula (2007), dentre vários outros.

${ }^{8}$ Cabe explicitar que, no âmbito do GEALE, é mobilizado o conceito de erro definido com base na teoria piagetiana, segundo a qual o erro (de fala ou de escrita) é parte do processo de aprendizagem. Nessa perspectiva, erros evidenciam hipóteses construídas pelos aprendizes na sua relação com o objeto a ser aprendido. Essa noção de erro é distinta daquela mobilizada por Zorzi (1997), para quem erro pode ser sintoma de distúrbio de aprendizagem.
} 
pressupostos teóricos, quer do modelo relation-based de Fonologia Prosódica

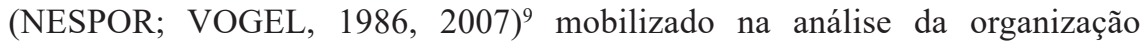
prosódica dos enunciados, quer da concepção do modo heterogêneo de constituição da escrita (CORRÊA, 2004).

Sobre esses pressupostos, cabe esclarecer brevemente duas noções fundamentais do arcabouço da fonologia prosódica, relevantes para o desenvolvimento deste artigo. No modelo adotado da fonológica da prosódia, uma assunção central é que relações sintáticas - ao lado de informações morfológicas e semânticas - são informações relevantes a partir das quais se configuram os constituintes prosódicos. Outra assunção importante é que os constituintes prosódicos não são necessariamente isomórficos aos demais constituintes gramaticais. Por exemplo, um sintagma nominal (SN) constituído de substantivo e adjetivo constitui dois sintagmas fonológicos $(\phi)$ quando a relação for substantivo-adjetivo, como em: $[\text { livros bons }]_{\mathrm{SN}}=[\text { livros }]_{\phi}[\text { bons }]_{\phi}$ Porém, se a relação for adjetivo-substantivo, o sintagma nominal será mapeado como um sintagma fonológico, como em: [bons livros $]_{\mathrm{SN}}=[\text { bons livros }]_{\phi} \cdot \mathrm{Ou}$ seja, um constituinte prosódico é criado a partir de informação de constituinte sintático, mas não há necessariamente isomorfia entre esses constituintes. Essa assunção sobre não isomorfia é especialmente importante para análise de dados de escrita, como será exemplificado mais à frente. Por fim, é importante explicitar que, nesse modelo, a hierarquia entre os constituintes prosódicos são, em ordem crescente: sílaba $(\sigma)$, pé métrico $(\Sigma)$, palavra prosódica $(\omega)$, grupo clítico (GC), sintagma fonológico $(\phi)$, sintagma entoacional (I) e enunciado fonológico $(\mathrm{U}) .^{10}$

Com base nesse arcabouço teórico, Tenani (2011a) analisa amostra transversal de textos produzidos no sexto ano do EF, e identifica predominância, dentre os casos de hipersegmentação, de a sílaba pretônica de uma palavra ortográfica ser analisada como clítico, como em "na quela". Já dentre os casos de hipossegmentação, foram identificadas duas estruturas principais, a saber: (i) um clítico foi grafado junto à palavra fonológica que o seguia, como "meajuda" e (ii) um clítico foi grafado junto à palavra fonológica que o precedia, como "ajudime". Em comum, as hipo e hipersegmentações envolveram, predominantemente, grafia de clíticos fonológicos. ${ }^{11}$ No conjunto dos dados analisados, foram identificados

${ }^{9}$ Vale lembrar que, ao lado do modelo relation-based, há o modelo end-based proposto inicialmente em Selkirk (1984). Nesse modelo, é a fronteira sintática a informação a partir da qual constituintes prosódicos são construídos.

${ }^{10}$ Os símbolos usados para representar cada domínio são os originalmente apresentados em Nespor e Vogel (1986, 2007). Vale retomar aqui a observação feita em Tenani (2017, p. 122), sobre haver variação na tradução dos termos do inglês para o português. Para "prosodic word", a preferência é por "palavra prosódica", podendo ser encontrada a denominação "palavra fonológica". Para "phonological phrase", registram-se "frase fonológica" e "sintagma fonológico". Para "intonational phrase", encontram-se "frase entoacional" e "sintagma entoacional".

11 Clíticos fonológicos compreendem, predominantemente, palavras gramaticais (como preposições, conjunções, pronomes, artigos) desprovidas de acentos. Uma caracterização mais detalhada é feita em Tenani (2016). 
como mais relevantes os constituintes $\omega$ e $C G,{ }^{12}$ sendo a flutuação entre um e outro constituinte traço característico das segmentações não-convencionais: quando houve hipersegmentação, a $\omega$ foi analisada como se se tratasse de $C G$, como em "da quele", "morava-mos"; quando houve hipossegmentação, um $C G$ foi analisado como se fosse uma $\omega$, como em "porfavor", "pegalo".

Essa flutuação entre hipo e hipersegmentação em textos de alunos do sexto ano do EF foi interpretada como tendo sido motivada por dificuldades com a identificação de monossílabos átonos que correspondem - no caso das hipossegmentações - e que os alunos parecem supor corresponderem - no caso das hipersegmentações - às chamadas palavras gramaticais (como preposições, conjunções e pronomes), as quais pertencem a categorias gramaticais que não têm seus usos sistematizados nos anos iniciais do EF, mas nos anos finais do EF. Essas grafias não-convencionais de monossílabos átonos são interpretadas como, em parte, motivadas pela prosodização de clíticos fonológicos junto a seu hospedeiro. Ora, o grupo clítico é o domínio em que, teoricamente, está prevista essa prosodização. No entanto, o grupo clítico como constituinte prosódico suscita discussão entre os estudiosos do tema, tendo sido apresentados argumentos a favor (BISOL, 2000, 2005) e contra (SIMIONI, 2008) a pertinência desse constituinte em português, como em várias outras línguas naturais. A busca por evidências que levem a embasar uma formalização da prosodização de clíticos é um campo ainda pouco investigado por demandar avanço teórico sobre a interface sintaxefonologia. Esse avanço é, em certa medida, instigado pelas flutuações ortográficas entre grafias convencional e não-convencional envolvendo monossílabos átonos que ocorrem em todos os anos do EF.

Em uma abordagem descritiva de textos de sexto a nono anos do EF, Tenani (2011b) mostra em que medida há evidências da organização prosódica do português em enunciados escritos. Foi argumentado que as segmentações não-convencionais de palavra ao longo dos anos do EF II seriam motivadas por, principalmente, três estruturas prosódicas da língua, a saber: $\Sigma,{ }^{13} \omega$ e $C G$. Mais especificamente, nas hipersegmentações, houve evidência da atuação do pé troqueu dissílabo (como em "dele gato" [delegado]) e, nas hipossegmentações, do $C G$ (com predomínio de próclise, como em "concerteza"). Também foi mostrado que os constituintes prosódicos relevantes para caracterizar as hipo e hipersegmentações encontradas nos textos do EF II diferem daqueles relevantes para os dados encontrados nos textos do EF I. Mais exatamente, no EF I, pode ser observada a atuação de todos os constituintes da hierarquia prosódica como demonstram Capristano (2007a) e Chacon (2011). ${ }^{14}$

${ }^{12}$ Palavra prosódica, constituída pela relação entre informações morfológicas sobre formação de palavra e informações fonológicas, tem o acento (lexical) como característica fonológica central; grupo clítico é a unidade que compreende um elemento clítico (isto é, elemento que não corresponde a afixos, nem a palavras prosódicas, desprovido de acento) e seu hospedeiro (isto é, uma palavra prosódica, portadora de acento).

${ }^{13} \mathrm{O}$ pé métrico consiste em uma cadeia de sílabas que constituem uma palavra prosódica, sendo atribuído a uma sílaba o valor forte e às demais valor fraco. O pé troqueu configura-se quando uma sílaba forte é seguida por outra átona (como em "cama, mesa, banho").

${ }^{14}$ Os dados de (1.1) a (1.3) foram selecionados de Chacon (2011) e os dados de (1.4) a (1.6) de Capristano (2007a). Mantem-se a grafia dos exemplos em maiúsculas como nos originais. 
Exemplifica-se, em (1.1), uma hipossegmentação de palavras que correspondem a um enunciado fonológico $(U) ;{ }^{15}$ em (1.2), hipossegmentação entre palavras que correspondem a uma frase entoacional $(I) ;{ }^{16} \mathrm{em}(1.3)$, hipossegmentação de palavras que constituem uma frase fonológica $(\phi) ;{ }^{17} \mathrm{em}(1.4)$, hipossegmentação de palavra mais um clítico formando um $G C$; em (1.5), hipersegmentação de palavra que revela clítico e palavra prosódica $(\omega) ;{ }^{18} \mathrm{em}(1.6)$, hipersegmentação de palavra delimitando pés métricos $(\Sigma)$.

\section{1. "ELEEARTERO” (“ELE É ARTEIRO”)}

\section{2. "TEUMAPEMASO" ([O SACI] "TEM UMA PERNA SÓ")}

\section{3. "SUMACASISO" ("FUMA CACHIMBO")}

\section{4. "FONO" ("FOI NO" [DIA DO CASAMENTO])}

\section{5. "EM TÃO” ("ENTÃO”)}

\section{6. "FELIZ BINA" ("FELIZBINA")}

Já no EF II não houve dados de escrita que envolvessem fronteiras de constituintes mais altos da hierarquia prosódica, como $I$ e $U$, tendo sido identificadas evidências de segmentações não-convencionais de palavras relacionadas a fronteiras de $\Sigma, \omega$ e $C G$, como anteriormente exemplificado. Portanto, em comum, verificou-se a atuação do acento (predominantemente o acento lexical no EF I e II, além de acento rítmico, em menor frequência no EF II), como ancoragem prosódica para delimitação de fronteira de palavra no processo de representar na escrita a segmentação do texto em unidades. Nessa comparação entre dados de escrita produzidas ao longo do EF, há pistas de que o sujeito escrevente iniciaria seu processo de produção escrita lançando âncoras nos constituintes mais altos da hierarquia prosódica (definidos por propriedades entoacionais e rítmicas dos enunciados) avançando para ancoragem em constituintes mais baixos dessa hierarquia nesse processo de aquisição (e desenvolvimento) da escrita. ${ }^{19}$

${ }^{15}$ Enunciado fonológico é o maior constituinte prosódico e abrange frases entoacionais. Seus limites são definidos a partir dos limites de sentença.

${ }^{16}$ Frase entoacional é constituinte definido pelas fronteiras de contornos entoacionais, podendo corresponder a uma sentença sintaticamente complexa (como em "A Marina escreveu perguntando se a encomenda havia chegado") ou a uma única palavra (como em "Socorro!").

${ }^{17}$ Frase fonológica caracteriza-se a partir da configuração de sintagmas definidos pela sintaxe, por exemplo, "Saci fuma cachimbo" configura-se em três frases fonológicas: [saci] [fuma] [cachimbo].

${ }^{18}$ Observo que também é possível interpretar "em tão" como sequência de duas sílabas.

${ }^{19}$ Cabe ponderar que esse (aparente) processo top-down de registro de constituintes na escrita, no entanto, não se mostra transparente, nem se constitui em percurso obrigatório a todo escrevente em processo de aquisição da escrita. Grafias que podem ser motivadas por um dos três constituintes mais altos da hierarquia prosódica não são maioria nos dados de crianças. 
Para além de serem identificadas semelhanças e diferenças, em termos de constituintes prosódicos, entre os dados de escrita produzida em diferentes ciclos do EF, encontraram-se pistas da natureza desses dados e de como são estabelecidas relações entre fala e escrita por crianças e adolescentes. Por meio das análises empreendidas por Tenani $(2011 \mathrm{a}, \mathrm{b})$ a partir da amostra transversal de textos, foi explicitado em que medida e quais características dos enunciados falados são passíveis de serem observadas por meio das segmentações não-convencionais de palavras nos enunciados escritos. Foi argumentado que essas segmentações se constituem em dados linguísticos que, além de mostrarem fatos mais recorrentes da aquisição da escrita, poderiam ser interpretadas como marcas que resultam da conjunção das práticas orais/faladas e letradas/escritas (CORRÊA, 2004) e que permitem flagrar a presença do oral/falado no letrado/escrito.

\section{DADOS DE ESCRITA E A NOÇÃO DE PALAVRA}

Outra questão desafiadora às teorias fonológicas diz respeito justamente à noção de palavra prosódica, que é fundamental para tratar da segmentação não-convencional de palavras ortográficas. Discussão sobre a complexidade da noção de palavra é feita por Silva e Tenani (2014, pp. 51-64) a partir das considerações de Abaurre (1991a) sobre tratar como problema trivial da escrita a necessidade de se conhecerem os critérios convencionais que definem palavra ortográfica, para que, assim, textos possam ser segmentados em palavras convencionalmente.

Sobre essa questão, vale lembrar as considerações de Lemos (1998, p. 17), para quem a transformação simbólica operada pela escrita faz com que, muitas vezes, seja negligenciada a relação que aquele que não sabe ler tem com os sinais gráficos que se apresentam transparentes para os que sabem ler. Essa condição dos considerados "alfabetizados" torna-os "de certa maneira, 'surdos' para as características mais contínuas dos enunciados orais" (ABAURRE, 1991a, p. 203) e, desse modo, ouvem palavras como unidades morfossintáticas organizadas sintagmaticamente conforme estabelecem as convenções ortográficas.

Ainda que seja inegável o fato de que, em uma sociedade predominantemente letrada como a nossa, os sujeitos (alfabetizados ou não) deem mostras de uma representação de que haja na escrita unidades gráficas, não se pode afirmar que os alunos já "compartilhem dos critérios morfossintáticos e semânticos utilizados [...] na identificação das palavras" (ABAURRE, 1991a, p. 204), até mesmo porque não estão "habituados à reflexão metalinguística que tal segmentação pressupõe" (ABAURRE et al., 1984, p. 27).

Cabe retomar, ainda de Silva e Tenani (2014, p. 22), a consideração de que "palavra não é um objeto de investigação facilmente definível, já que suas funções e seus limites não são definidos a priori". Os desafios envolvidos no estudo de palavra são explicitados por Veloso (2016, p. 14) nos seguintes termos: 
confrontamo-nos, em linguística, com uma contradição entre, por um lado, as intuições dos falantes - que geralmente possuem uma noção implícita bastante nítida do que entendem por palavra e se mostram intuitivamente capazes de identificar e de isolar palavras num continuum verbal - e, por outro, a dificuldade de encontrarmos critérios estritamente linguísticos [...] que permitam uma definição satisfatória da noção de palavra e sua identificação/delimitação em continua linguísticos mais extensos.

Dessas considerações, enfatizo a complexidade linguística da noção de palavra e, especialmente, sua identificação/delimitação em um enunciado (seja falado ou escrito). Neste artigo, grafias não-convencionais das fronteiras de palavra são discutidas por se constituírem em indícios dessa complexidade da unidade linguística "palavra", característica pouco notada (e tantas vezes esquecidas) por parte daqueles que escrevem segundo as convenções ortográficas. De modo mais explícito: segmentações não-convencionais de palavra tornam visível o fato de que fronteiras de constituintes morfossintáticos e semânticos, que embasam (em parte) as convenções de fronteiras de palavra na escrita, ${ }^{20}$ não correspondem a fronteiras de constituintes prosódicos (especialmente $\omega)$, que se configuram com base em critérios rítmicos e entoacionais e que guiam (em certa medida) os alunos em aquisição e desenvolvimento da escrita a segmentarem seus textos em unidades distintas daquelas adotadas pelas convenções ortográficas. ${ }^{21}$

Interessa exemplificar três lócus de não correspondências entre fronteiras de palavras definidas pelas convenções ortográficas e fronteiras de constituintes prosódicos: o primeiro diz respeito às chamadas palavras compostas, exemplificadas em (1.7); o segundo, a um conjunto de palavras derivadas, exemplificadas em (1.8); o terceiro, às chamadas palavras gramaticais não acentuadas, exemplificadas em (1.9).

1.7. i. $\quad[\text { espaçonave }]_{\omega}=[\text { espaço }]_{\omega}[\text { nave }]_{\omega}$

ii. $[\text { mesa-redonda }]_{\omega}=[\text { mesa }]_{\omega}[\text { redonda }]_{\omega}$

1.8. i. $\quad[\text { simplesmente }]_{\omega}=[\text { simples }]_{\omega}[\text { mente }]_{\omega}$

ii. $[\text { autoditata }]_{\omega}=[\text { auto }]_{\oplus}[\text { ditada }]_{\omega}$

1.9. i. $\quad\left[\right.$ de $_{\omega}\left[\right.$ novo $_{\omega}=[\text { de novo }]_{\mathrm{GC}}$

ii. $[j o g a ́]_{\omega}[10]_{\omega}=[j o g a ́-l o]_{\mathrm{GC}}$

\footnotetext{
${ }^{20}$ Vale lembrar que convenções ortográficas são também constituídas sócio-historicamente a partir de práticas letradas (de leitura e escrita) tal como discutido por Tenani (2016).

${ }^{21}$ Uma abordagem a respeito de noções sobre palavras, mobilizadas pelos alunos e advindas de suas práticas letras/escritas, pode ser encontrada em Tenani (2016).
} 
Em (1.7), as palavras "espaçonave" e "mesa-redonda" são compostas por duas palavras lexicais, constituindo, cada uma delas, uma palavra morfológica (w). Quanto às convenções ortográficas, a fronteira entre as palavras lexicais é marcada por hífen apenas em "mesa-redonda", não ficando delimitada em "espaçonave”. Nos dois casos, a ortografia registra os limites da palavra morfológica. Fonologicamente, nos dois exemplos, há duas palavras prosódicas, pois são preservados os acentos de cada uma das palavras lexicais. Por meio desses exemplos, demonstra-se a relevância da interação entre critérios fonológicos e morfológicos para a caracterização da noção de palavra. Faz-se importante, portanto, distinguir entre palavra prosódica (ou fonológica) e morfológica, tal como proposto por Bisol (2004, p. 59):

A primeira [morfológica] compreende palavras lexicais, como nome, adjetivo e verbo, classes abertas, e palavras funcionais como preposição, conjunção e determinativos, classes fechadas. A segunda [fonológica] distingue palavras com acento e sem acento, respectivamente palavras fonológicas e clíticos (grifos acrescentados).

Em (1.8), "simplesmente” é uma palavra morfológica constituída da palavra lexical "simples" e o sufixo derivacional "mente". Fonologicamente, "simples" e "mente" mantêm seus acentos, constituindo duas palavras prosódicas, embora uma morfológica. Já "autodidata" é uma palavra morfológica constituída do prefixo "auto" e da palavra lexical "didata". Fonologicamente, "auto" e "didata" preservam seus acentos, constituindo, cada um, uma $\omega$. Portanto, há palavras morfológicas (derivadas por certos sufixos ou por certos prefixos) que correspondem a duas palavras prosódicas. ${ }^{22}$

Em (1.9), as palavras morfológicas "de" e "lo" compreendem palavras gramaticais que dependem sintaticamente das palavras lexicais que lhe são adjacentes, ou seja, a preposição "de" depende do adjetivo "novo" que a segue; a forma pronominal "lo", da forma verbal "joga" que a precede. Fonologicamente, essas palavras gramaticais não têm acento e, por essa razão, são clíticos fonológicos, ou seja, são palavras morfológicas que não têm status de $\omega$. Essa relação morfossintática entre palavras morfológicas em que uma delas é um clítico fonológico é interpretada como característica do $C G$, constituinte prosódico assim denominado na teoria fonológica adotada.

Por meio dessas considerações, ficam explicitados um fato e uma hipótese. O fato é que as fronteiras de palavra definidas pelas convenções ortográficas (palavras ortográficas) são definidas, em grande parte, com base em fronteiras de palavra morfológicas e essas fronteiras são distintas daquelas dos constituintes prosódicos (palavras prosódicas, grupos clíticos). A hipótese explicativa principal para as ocorrências de segmentações não-convencionais de palavra estaria na não correspondência entre fronteiras de palavra morfológica e de constituintes prosódicos, como $\omega$ e $C G$. Em Tenani (2016), argumenta-se que a essa hipótese deve-se, também, considerar a configuração prosódica do enunciado em que ocorrem as palavras que são segmentadas não-convencionalmente, dada a relevância da organização rítmica e entoacional dos enunciados para a produção escrita.

${ }^{22}$ Detalhes sobre o funcionamento de palavra compostas, veja-se Bopp da Silva (2010). Sobre o funcionamento dos prefixos acentuados, veja-se discussão feita por Schwindt (2000). 
Portanto, segmentar um texto em palavras segundo as convenções ortográficas implicaria mobilizar fronteiras de constituintes definidos a partir de relações entre unidades lexicais e gramaticais de natureza prosódica, sintática e semântica (como detalhadamente discutido em Tenani, 2016). Os dados de escrita (iniciais ou não) trazem o desafio teórico-analítico a respeito da identificação de limites de palavra e, especialmente, de monossílabos átonos, na medida em que diferentes formalizações da prosodização dos clíticos são propostas a partir de evidências fonológicas, havendo argumentos tanto a favor quanto contrários à pertinência de um domínio que abarque as características da relação de clíticos fonológicos junto a seus hospedeiros. Acrescenta-se, ainda, que mesmo se admitida a pertinência desse domínio prosódico de prosodização de clíticos, não há consenso entre pesquisadores sobre sua adequada formalização.

Por fim, vale observar que segmentação de palavras está inserida em tema mais amplo sobre o processo de segmentar enunciados falados em unidades linguísticas, relevante para a aquisição da linguagem, por exemplo. Freitas et al. (2006) demonstram que há efeitos de frequência de ocorrências de unidades e padrões prosódicos relevantes para a identificação, pelas crianças, de regularidades silábicas do Português Europeu, por exemplo. Estudos de mesma natureza sobre o Português Brasileiro, cujas características prosódicas diferem das do Português Europeu, estão por ser realizados.

\section{CONSIDERAÇÕES FINAIS}

As pesquisas realizadas sobre segmentação não-convencional de palavra brevemente retomadas neste artigo - permitem identificar ao menos três aspectos relevantes para seu estudo no campo da Linguística, que dizem respeito à: (i) compreensão sobre relações entre fala e escrita mobilizadas pelos alunos quando da produção escrita, (ii) comprovação e/ou problematização de pressupostos de teorias fonológicas relevantes para descrever regularidades linguísticas observadas nos textos escritos e (iii) caracterização da noção de palavra, notadamente consideradas características de sua constituição enquanto unidade fonológica, morfossintática e semântica.

Esses três aspectos são importantes para embasar análises comprometidas em descrever e explicar o fato mais geral de que dados de escrita são resultados de hipóteses conflitantes sobre representações linguísticas dos enunciados (escritos e falados) que os escreventes elaboram a partir de sua multifacetada relação com a língua(gem) (TENANI, 2009, p. 109).

Por fim, à luz das considerações feitas acerca das noções de palavra (ortográfica, morfológica, prosódica), aceno para possíveis diálogos com profissionais da área de Educação comprometidos com a aquisição e o desenvolvimento da escrita. Procurei argumentar que análises de dados de escrita que mobilizam teorias fonológicas embasam argumentos contrários à interpretação das segmentações não-convencionais de palavras, quer como 
simples desvios das convenções ortográficas (decorrentes de falta de atenção do aluno ou de dificuldades de alfabetização vividas principalmente em escolas públicas ao longo do EF), quer como sintomas de disortografia (decorrentes de dificuldades de processamento cognitivo de alunos quanto a estabelecer relação entre fala e escrita). Neste artigo, busquei apresentar evidências que sustentam abordagem que privilegia a investigação de aspectos linguísticos, com ênfase nos de natureza fonológica, característicos de grafias não-convencionais de palavra que ocorrem em textos produzidos por alunos em processo formal de aquisição e desenvolvimento da escrita.

\section{$\overline{\text { REFERÊNCIAS }}$}

ABAURRE, M. B. M. O que revelam os textos espontâneos sobre a representação que faz a criança do objeto escrito? In: KATO, M. A. (Org.). A concepção da escrita pela criança. Campinas: Pontes Editores, 1988a, pp. 135-142.

ABAURRE, M. B. M. The interplay between spontaneous writing and underlying linguistic representations. European journal of psychology of education, Lisboa, v. III, n.4, pp. 415-430, $1988 \mathrm{~b}$.

ABAURRE, M. B. M. A relevância dos critérios prosódicos e semânticos na elaboração de hipóteses sobre segmentação na escrita inicial. Boletim da Abralin, Campinas, v. 11, pp. 203-17, 1991a.

ABAURRE, M. B. M. Ritmi dell'oralità e ritmi dela escritura. In: ORSOLINI, M. e PONTECORVO, C. La construzione del texto scritto nei bambini. Roma: La Nuova Italia, $1991 \mathrm{~b}$.

ABAURRE, M. B. M. Os Estudos Linguísticos e a aquisição da escrita. In: CASTRO, M. F. C. P. (Org.). O método e o dado no estudo da linguagem. Campinas: Editora da Unicamp, 1996, v. 1, pp. 111-163.

ABAURRE, M. B. M. et alii. Leitura e escrita na vida e na escola. In: Leitura: Teoria \& Prática, Campinas, n. 6, 1984, pp. 15-26.

ABAURRE, M. B. M.; SILVA, A. O desenvolvimento de critérios de segmentação na escrita. Temas em psicologia. São Paulo, v. 1, pp. 89-102, 1993.

BALIEIRO JR., A. P, Psicolinguística. In: MUSSALIN, F.; BENTES, A. C. Introdução à linguística: domínios e fronteiras. São Paulo: Cortez, 2001, pp.171-201.

BISOL, L. O clítico e seu status prosódico. Revista de Estudos da Linguagem, Belo Horizonte, v. 9, n.1, pp. 5-20, 2000.

BISOL, L. Mattoso Câmara Jr. e a Palavra Prosódica. DELTA, São Paulo. v. 20, n. especial, pp. 59-70, 2004.

BISOL, L. O clítico e o seu hospedeiro. Letras de Hoje, Porto Alegre, v. 40, n. 3, pp. 163-184, 2005.

BOPP DA SILVA, T. Formação de palavras compostas em português brasileiro: uma análise de interfaces. Porto Alegre, 2010, 195f. Tese (Doutorado em Letras) - Universidade Federal do Rio Grande do Sul, 2010.

CAPRISTANO, C. C. A propósito da escrita do EF I: uma reflexão sobre as segmentações nãoconvencionais. Letras de Hoje, Porto Alegre, v. 39 n. 3, pp. 245-260, 2004. 
CAPRISTANO, C. C. Mudanças na trajetória da criança em direção à palavra escrita. 253f. Tese (Doutorado em Linguística Aplicada) - Instituto de Estudos da Linguagem, Universidade Estadual de Campinas, Campinas, 2007a.

CAPRISTANO, C. C. Aspectos de segmentação na escrita do EF I. São Paulo: Martins Fontes. $2007 \mathrm{~b}$.

CAPRISTANO, C. C.; TICIANEL, G. F. Discurso direto e hipossegmentações na escrita infantil. Filologia e Linguística Portuguesa, São Paulo, v. 16, pp. 233-259, 2014.

CHACON, L. Constituintes prosódicos e letramento em segmentações não-convencionais. Letras de Hoje, Porto Alegre, v. 39, n. 3, pp. 223-232, 2004.

CHACON, L. Hipersegmentações na escrita do EF I: entrelaçamento de práticas de oralidade e de letramento. Estudos Linguísticos, Campinas, v. 34, pp. 77-86, 2005.

CHACON, L. Prosódia e letramento em hipersegmentações: reflexões sobre a aquisição da noção de palavra. In: CORRÊA, M. L. G. (org.) Ensino de língua: representação e letramento. Campinas: Mercado de Letras, pp.155-167, 2006.

CHACON, L. Segmentações não-convencionais na escrita de pré-escolares: entrecruzamentos entre convenções ortográficas e constituintes prosódicos. In: Regina Ritter Lamprecht. (Org.). Aquisição da linguagem: estudos recentes no Brasil. Porto Alegre: Editora da PUC-RS, 2011, pp. 251-261.

CHOMSKY, N. Linguagem e mente. Trad. Roberto Leal Ferreira. 3.ed. São Paulo: Editora da UNESP, 2009 .

CORRÊA, M. L. G. O modo heterogêneo de constituição da escrita. São Paulo: Martins Fontes. 2004.

CUNHA, A. P. N. A hipo e a hipersegmentação nos dados de aquisição da escrita: um estudo sobre a influência da prosódia, 2004. 132f. Dissertação (Mestrado em Educação) - Faculdade de Educação, Universidade Federal de Pelotas, Pelotas, 2004.

CUNHA, A. P. N. As segmentações não-convencionais da escrita inicial: uma discussão do ritmo linguístico do português brasileiro e europeu, 2010. 188f. Tese (Doutorado em Educação) Faculdade de Educação, Universidade Federal de Pelotas, Pelotas, 2010.

CUNHA, A. P. N.; MIRANDA, A. R. M. Indícios de reestruturação do conhecimento fonológico da criança em dados de reparo na escrita inicial. Letras de Hoje, Porto Alegre, v. 48, n. 3, pp. 343-354, 2013

FERREIRA, C. R. G. Um estudo sobre a segmentação não convencional na aquisição da escrita de alunos de EJA. 2011. 163f. Dissertação (Mestrado em Educação) - Faculdade de Educação, Universidade Federal de Pelotas, Pelotas, 2011.

FERREIRO, E; TEBEROSKY, A. Psicogênese da lingua escrita. Trad. Diana Myriam Lichtenstein, Liana Di Marco e Mário Corso. Porto Alegre: Artes Médicas Sul, 1999.

FREITAS et al. Efeitos prosódicos e efeitos de frequência no desenvolvimento silábico em Português Europeu. In XX Encontro Nacional da Associação Portuguesa de Linguística. Textos Seleccionados. Lisboa: APL/Colibri, pp. 397-412. 2006.

LEMOS, C. Teorias da Diferença e Teorias do Déficit: reflexões sobre programa de intervenção na pré-escola e na alfabetização. In: Anais do Seminário Multidisciplinar de Alfabetização, 11 a 13 de agosto de 1983. Brasília: INEP, 1984, pp. 133-145. Disponível em: http://www. dominiopublico.gov.br/pesquisa/DetalheObraForm.do?select_action=\&co_obra=27629. Acesso em 10 de maio de 2016. 
LEMOS, C. Sobre a aquisição da escrita: algumas questões. In: ROJO, R. (Org.) Alfabetização e letramento: perspectivas linguísticas. São Paulo: Mercado de Letras, pp. 13-32, 1998.

NESPOR, M. ; VOGEL, I. Prosodic phonology. Dordrechet: Foris Publications, 1986.

NESPOR, M.; VOGEL, I. Prosodic phonology: with a new foreword. Berlin; New York: Mouton de Gruyter. 2007.

PAULA, I. F. V. Movimentos na escrita inicial de crianças: um estudo longitudinal de hipersegmentações. São José do Rio Preto, 2007. 132f. Dissertação (Mestrado em Estudos Linguísticos) - Instituto de Biociências, Letras e Ciências Exatas, Universidade Estadual Paulista, 2007.

SCARPA, E. Aquisição da linguagem. In: MUSSALIN, F.; BENTES, A. C. Introdução à linguística: domínios e fronteiras. São Paulo: Cortez, 2001, pp. 203-232.

SCHWINDT, L. C. O prefixo no Português Brasileiro: análise morfofonológica. 2000. $191 \mathrm{f}$. Tese (Doutorado em Letras) - Faculdade de Letras, Pontifícia Universidade Católica do Rio Grande do Sul, Porto Alegre, 2000.

SEKIYAMA, K.; BURNHAM, D. Issues in the development of auditory-visual speech perception: Adults, infants, and children. In: Eighth International Conference on Spoken Language Processing, pp. 1137-1140, 2004.

SEMINÁRIO MULTIDISCIPLINAR DE ALFABETIZAÇÃO (São Paulo, 11 a 13 de agosto de 1983). Anais... Brasília: INEP, 1984. 158p. Disponível em: http://www.dominiopublico.gov.br/pesquisa/ DetalheObraForm.do?select_action=\&co_obra=27629. Acesso em: 10 de set. 2016.

SILVA, A. Alfabetização: a escrita espontânea. São Paulo: Contexto, 1991.

SILVA, L. M.; TENANI, L. Hipersegmentações de palavras no ensino fundamental. São Paulo: Cultura Acadêmica, 2014.

SIMIONI, T. O clítico e seu lugar na estrutura prosódica em Português Brasileiro. ALFA, São Paulo, v. 52, n.2, pp. 431-446, 2008.

TENANI, L. Segmentações não convencionais e teorias fonológicas. Letras de hoje. Porto Alegre, v. 39, n. 3, setembro, pp. 233-244, 2004.

TENANI, L. A segmentação não convencional de palavras: evidências de representações de relações entre enunciados falados e escritos. Anais do II SIMELP "Língua portuguesa: ultrapassar fronteiras, juntar culturas", pp. 107-127, 2009.

TENANI, L. A grafia dos erros de segmentação não-convencional de palavras. Cadernos de Educação, Pelotas, v. 35, pp. 247-269, 2010.

TENANI, L. Letramento e segmentações não-convencionais de palavras. In: TFOUNI, L. V. (Org.). Letramento, escrita e leitura: Questões Contemporâneas. Campinas: Mercado de Letras, pp. 229-243, 2011a.

TENANI, L. A segmentação não-convencional de palavras em textos do ciclo II do ensino fundamental. Revista da Associação Brasileira de Linguística, v. 10, n. 2, pp.91-119, 2011b.

TENANI, L. Hipersegmentação de palavras: análise de aspectos prosódicos e discursivos. Linguagem \& Ensino, Pelotas, v. 16, pp. 305-324, 2013.

TENANI, L. Fonologia prosódica. In: DERMEVAL, H.; MATZENAUER, C. (Org.) Fonologia, fonologias. São Paulo: Contexto, 2017, pp. 109-123. 
TENANI, L.; PARANHOS, L. C. Análise Prosódica de segmentações não-convencionais de palavras em textos do sexto ano do EF. Filologia e Linguística Portuguesa, São Paulo, v. 13, pp. 477-504, 2011.

VELOSO, J. Verba manent: a palavra como unidade pertinente para a descrição linguística do português e de outras línguas flexionais. Porto Alegre: EDIPUCRS, 2016.

VYGOSTSKY, L. S. A formação social da mente: o desenvolvimento dos processos psicológicos superiores. São Paulo, Martins Fontes, 1988.

ZORZI, J. L. A apropriação do sistema ortográfico nas 4 primeiras séries do primeiro grau. Campinas, 1997. 124f. Tese (Doutorado em educação) - Faculdade de Educação, Universidade Estadual de Campinas (UNICAMP), Campinas, 1997. 